\title{
On the postnatal development of the striate cortex (V1) in the tree shrew (Tupaia belangeri)
}

\author{
Ulrich Drenhaus, ${ }^{1}$ Günter Rager, ${ }^{1}$ Peter Eggli ${ }^{2}$ and Robert Kretz ${ }^{1}$ \\ ${ }^{1}$ Department of Medicine, Division of Anatomy, University of Fribourg, 1700 Fribourg, Switzerland \\ ${ }^{2}$ Institute of Anatomy, University of Bern, 3000 Bern, Switzerland
}

Keywords: 3D reconstructions, cortex-shifting, morphometry, visuotopic topography

\begin{abstract}
Histological serial sections, three-dimensional reconstructions and morphometry served to study the postnatal development of $\mathrm{V} 1$ in tree shrews. The main objectives were to evaluate the expansion of $\mathrm{V} 1$, the implications of its growth on the occipital cortex and, vice versa, the effects of the expanding neocortex on the topography of V1. The future V1 was identified on postnatal day 1 by its granular layer IV, covering the superior surface of the occipital cortices including the poles. A subdivision of layer IV, distinctive for the binocular part, was evident in the central region. V1 expanded continuously with age into all directions succeeded by the maturation of layering. The monocular part was recognized from day 15 onward, after the binocular part had reached its medial border. In reference to the retinotopic map of $\mathrm{V} 1$, regions emerged in a coherent temporo-spatial sequence delineating the retinal topography in a central to peripheral gradient beginning with the visual streak representation. The growth of $\mathrm{V} 1$ was greatest until tree shrews open their eyes, culminated during adolescence, and completed after a subsequent decrease in the young adult. Simultaneous expansion of the neocortex induced a shifting of V1. Translation and elongation of V1 entailed that the occipital cortex covered the superior colliculi along with a downward rotation of the poles. The enlargement of the occipital part of the hemispheres was in addition associated with the formation of a small occipital horn in the lateral ventricles, indicating an incipient 'true' occipital lobe harbouring mainly cortices involved in visual functions.
\end{abstract}

\section{Introduction}

Tree shrews, native in south-east Asia, are diurnal mammals that share morphological features with insectivores and primates. This led to the assumption that tree shrews derived from a basal stock of Mesozoic insectivore Eutheria close to the origin of primates (Martin, 1990). Tree shrews are nowadays positioned as a separate order Scandentia with the extant species integrated into the families Tupaiidae and Ptilocercidae (Olson et al., 2005).

The phylogenetic descent of tree shrews is reflected in the CNS. Their brain is lissencephalic, being infero-laterally indented by a prominent rhinal sulcus that separates the neocortex from the palaeocortex (Starck, 1982). The olfactory bulb and the piriform cortex are smaller than in insectivores. Diencephalic nuclei are partially well differentiated; the pulvinar is a separate entity, and the structure of the dorsal lateral geniculate nucleus resembles the primate pattern (Simmons, 1981). The expansion of the neocortex links up with primitive primates (Frahm et al., 1984). It induced a rotation of the hemispheres with the formation of a modest temporal lobe. The occipital part of the neocortex expands even after birth and entails that the occipital poles eventually conceal the superior colliculi (Zilles, 1978b).

The occipital neocortex harbours the visual cortices. The primary visual cortex (V1, striate cortex, area striata, or area 17 of Brodmann) can, according to Kaas et al. (1972), be functionally subdivided into a

Correspondence: Dr U. Drenhaus, as above.

E-mail: ulrich.drenhaus@unifr.ch binocular and a monocular part (Fig. 1). The triangular-shaped binocular part occupies the supero-lateral surface of the occipital neocortex including the poles and the medial wall, the smaller monocular part locates on the inferior surface only (Kaas, 1980). Both parts are visuotopically organized (Kaas et al., 1972; Kretz et al., 1986). V1 is surrounded by secondary and tertiary visual cortices, and their size approaches the lower part of the prosimian range (Frahm et al., 1984). In primates, the visual system provides the main sensory input. The respective cortices are substantially expanded, associated with the formation of an occipital lobe and a downward rotation of the poles (Starck, 1982). It is hypothesized that the progressive evolution of the visual system initiated in the early phase of development from insectivores to prosimians (Frahm et al., 1984).

The phylogenetic descent and the postnatal expansion of the occipital part of the hemispheres make tree shrews an interesting model to investigate the growth of V1 in relation to the extension of the occipital cortex. V1 can be discerned 4 days before birth and develops mainly postnatally (Zilles, 1978b). The course of its spreading is unknown. Therefore, we investigated the temporal and spatial expansion of V1 from postnatal day 1 (P1) to adulthood. We examined also the contribution of V1 to the expansion of the occipital parts of the hemispheres, whether this expansion is merely a translation or whether it includes already a downward rotation of the occipital poles. Finally, we addressed the question whether the enlargement of the occipital cortex is associated with an incipient occipital lobe characterized by the development of an occipital horn in the lateral ventricles. 


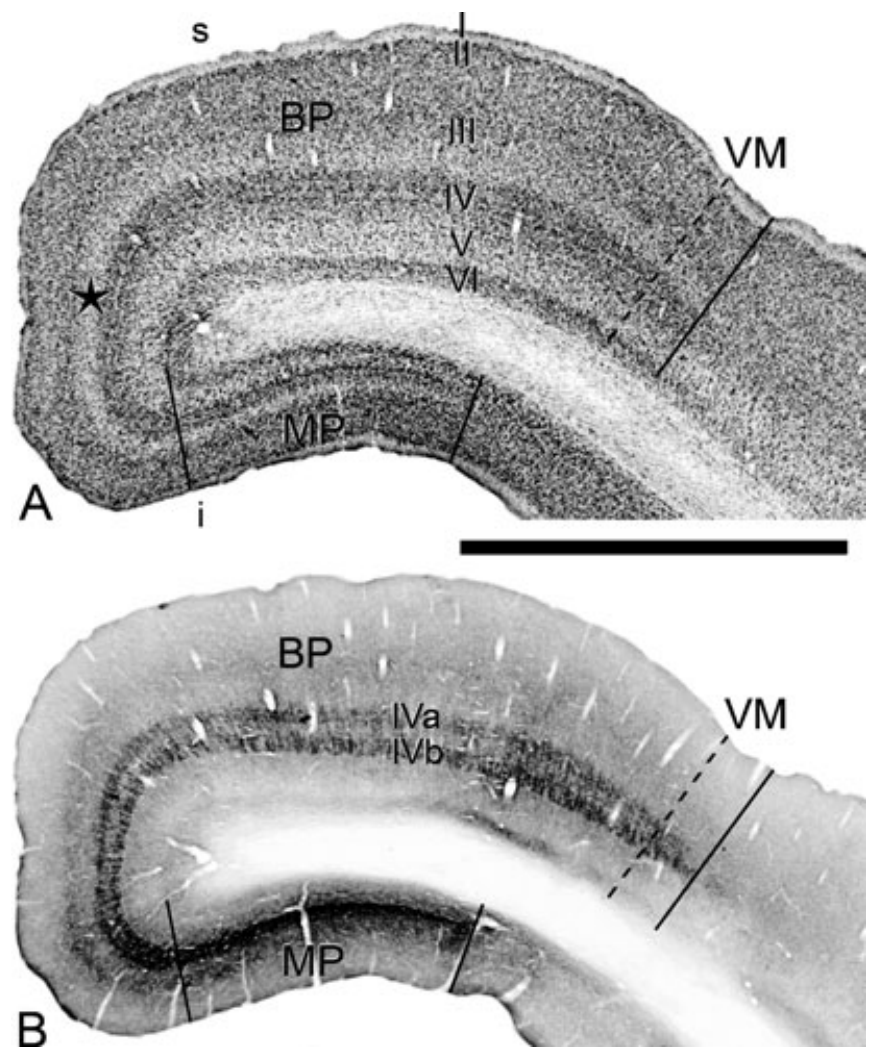

FIG. 1. Micrographs of 52- $\mu$ m-thick neighbouring frontal sections of the left V1 of an adult animal stained with Cresyl violet (A) and treated with cytochrome oxidase histochemistry (B). The numbers I-VI in (A) indicate the six layers of the cortex, sublayers IVa and IVb are labelled in (B). The comparison shows that the Nissl stain allows a clear identification of V1 with its conspicuous granular layer IV. V1 on the superior surface (s) and the medial wall (black star) up to the adjacent inferior side (i) corresponds to the binocular part (BP; Kaas, 1980). Its layer IV is well differentiated into the sublayers IVa and IVb separated by a cell-sparse cleft. The supero-lateral rim of the binocular part, characterized by a smaller layer IV, represents the ipsilateral visual field (Bosking et al., 2000). It is demarcated by the vertical meridian (VM), the approximate position of which is indicated by the broken line. On the inferior surface layer IV is rather small and the sublayers are merged (Wong-Riley \& Norton, 1988), indicating the monocular part (MP), which receives visual information from the contralateral eye (Kaas, 1980). In the MP, at the layer IV$\mathrm{V}$ border, pyramidal neurons of layer V can form a cell-dense zone. Scale bar, $2.5 \mathrm{~mm}$.

\section{Materials and methods}

Twelve tree shrews from P1 to P130 were investigated in detail (Table 1), in three animals (P4, P8, P14) only the histological differentiation of V1 was studied, three adult animals were used to evaluate the appropriate stain and the topography of the occipital cortex, respectively. Birth takes place on ontogenetic day $42.9 \pm 1.8$ (mean and standard deviation; $n=66$ ) and P0 signifies the day of birth; the animals open their eyes on P18.8 $\pm 2.1(n=87)$. The animals were anaesthetized with Nembutal $(40 \mathrm{mg} / \mathrm{kg}$ body weight) and transcardially perfused with a $0.9 \% \mathrm{NaCl}$ solution quickly followed by $500-1000 \mathrm{~mL}$ (volume according to body size) of the fixative ( $4 \%$ paraformaldehyde dissolved in $0.1 \mathrm{M}$ phosphate buffer, $\mathrm{pH} 7.4$, room temperature). After dissection the brains were postfixed by immersion in the same fixative for an additional 22-72 $\mathrm{h}$ (duration depending on brain volume size), dehydrated, embedded in Paraplast Plus, sectioned serially at 15 or $20 \mu \mathrm{m}$, and stained with Cresyl violet (Böck, 1989). All experiments were carried out in accordance with the
TABLE 1. Age, body weight, weight of the whole brain and shrinkage factors of investigated animals

\begin{tabular}{|c|c|c|c|c|c|c|}
\hline \multirow{2}{*}{$\begin{array}{l}\text { Age } \\
\text { (postnatal } \\
\text { day) }\end{array}$} & \multirow{2}{*}{$\begin{array}{l}\text { Body } \\
\text { weight } \\
\text { (g) }\end{array}$} & \multirow{2}{*}{$\begin{array}{l}\text { Brain } \\
\text { weight } \\
\text { (g) }\end{array}$} & \multicolumn{4}{|c|}{ Shrinkage factor* } \\
\hline & & & Width & Height & Length & Total \\
\hline 1 & 13.0 & 0.78 & 0.74 & 0.64 & 0.78 & 0.37 \\
\hline 7.1 & 19.9 & 1.05 & 0.84 & 0.77 & 0.73 & 0.48 \\
\hline 7.2 & 61.0 & 1.70 & 0.86 & 0.85 & 0.87 & 0.63 \\
\hline 10 & 44.7 & 1.94 & 0.87 & 0.84 & 0.78 & 0.56 \\
\hline 11 & 27.3 & 1.15 & 0.81 & 0.86 & 0.85 & 0.59 \\
\hline 15 & 51.6 & 2.00 & 0.86 & 0.86 & 0.81 & 0.59 \\
\hline 16 & 41.3 & - & 0.76 & 0.72 & 0.82 & 0.45 \\
\hline 20 & 56.5 & 2.50 & 0.87 & 0.79 & 0.93 & 0.63 \\
\hline 22 & 133.3 & 2.60 & 0.85 & 0.77 & 0.92 & 0.60 \\
\hline 45 & 160.0 & 3.40 & 0.77 & 0.82 & 0.82 & 0.52 \\
\hline 66 & 186.0 & 3.05 & 0.91 & 0.82 & 0.97 & 0.73 \\
\hline 130 & 173.3 & 3.40 & 0.88 & 0.92 & 0.93 & 0.76 \\
\hline
\end{tabular}

*Quotient of corresponding measurements of reconstruction and brain.

guidelines published by the Swiss Academy of Medical Sciences and the Swiss Academy of Natural Sciences regarding the care and use of animals for experimental procedures.

V1 was identified by cytoarchitectonic criteria given by Zilles (1978a,b), particularly by its conspicuous granular fourth layer, which diminishes abruptly at the area boundaries (Diamond et al., 1970; Zilles, 1978b). The binocular part was distinguished from the monocular part by its larger cortical thickness and a thicker layer IV subdivided by a cell-sparse cleft into compact sublayers IVa and IVb (Glendenning et al., 1976; Conley et al., 1984; Lund et al., 1985). These sublayers merge in the monocular part (Wong-Riley \& Norton, 1988). A pilot study, where alternating sections were individually stained with Cresyl violet or treated with cytochrome oxidase histochemistry (Fig. 1), which labels layer IV throughout its whole length (Lund et al., 1985), proved that the extent of V1 and that of its two functional parts can properly be determined with the Nissl stain.

\section{Application of landmarks}

After perfusion fixation, the skin was detached and the superior and lateral parts of the skull were removed leaving the brain in situ fixed to the floor of the skull. In each animal, except P1 because of instabilities in fixation, the head was positioned in a stereotactic apparatus (David Kopf Instruments, Tujunga, CA, USA) and orientated according to the Frankfurter horizontal plane. Then, a needle (diameter: $0.3 \mathrm{~mm}$ ) was inserted from the occipital pole of each hemisphere parallel to the Frankfurter horizontal plane toward the anterior direction. The positions of these needles were recorded in reference to the longitudinal fissure of the telencephalon. The needles were removed and the resulting holes served as internal landmarks for later alignment. Then, the telencephalon was cut well in front of the chiasm parallel to the intra-aural line and perpendicular to the Frankfurter horizontal plane. This section plane served as reference for alignment of the Paraplast blocks for sectioning.

\section{Data acquisition}

The stained sections were photographed by means of magnifying glasses (Photomacroscope M400, Wild, Heerbrugg, Switzerland) at a magnification of $6.3 \times($ Agfa Pan negative film, 25 ASA, Agfa Gevaert AG, Dübendorf, Switzerland). The images were printed on 
photographic paper (Ilford, Fribourg, Switzerland) at a final magnification of $16 \times$. Occasionally missing sections were substituted by the preceding sections. The enlargements were used to trace individually the outlines of the following structures: the complete brain, the ventricles I-III, V1, the superior and inferior colliculi. Outlines of the anterior and posterior commissure, the visual pathway, the dorsal lateral geniculate body, putamen and caudate nucleus served mainly to monitor and adapt the alignment of sections. The procedure was controlled with the light microscope. The boundaries of V1 were marked off perpendicular to the cortical surface at the periphery of the granular layer IV. The isocontours were prepared with a waterproofed felt-tipped pen (diameter: $0.5 \mathrm{~mm}$ ) on transparent foils, marked with a bisecting line. They were placed onto the images with the thin line superposing the mid-sagittal line of the sections. The foils with the outlines were scanned at 600 dpi using a flat bed scanner (hp scanjet 5400c, Hewlett Packard) and stored as TIF-files in the computer. The pixel size of the scans in $\mathrm{X}$ and $\mathrm{Y}$ was determined at $10 \mu \mathrm{m}$ (according to the Nyquist theorem, the maximum pixel resolution is $50 \%$ of this size). The areas of the different structures as defined by their outlines were colour coded using the program KS400 version 3.0.0.3 (Carl Zeiss Vision $\mathrm{GmbH}$ ). The contour-lines were added at equal parts to the bordering structures; the midline of the foil was removed except for its extremities outside the brain. Based on the results of an evaluation (see Results), the contour-images were aligned using the landmarks or alternatively the maximal area of overlap of the brain structures. For alignment the program Autoaligner (version 2.0; Bitplane, Zürich, Switzerland) was used.

\section{$3 D$ reconstructions and morphometry}

The registered image stacks were used for $3 \mathrm{D}$ reconstructions after correction of shrinkage. The shrinkage in each plane (length, width and height of the hemispheres) was computed as the quotient of the measurements of the reconstruction and corresponding measurements of the pre-embedding brain. The reciprocal values provided the correction factors. Length and width of the hemispheres were measured after perfusion fixation, while the head was positioned in the stereotactic apparatus. At the same time, a first image of the exposed brains was taken. The completely dissected brains were again photographed in their superior, inferior and lateral views, and measured again.

The brain volume was calculated according to Zilles (1978b) as quotient of the brain weight and its specific gravity $\left(1.033 \mathrm{~g} / \mathrm{cm}^{3}\right)$. The volume of V1 was calculated by multiplying its number of voxels with their size. It was determined before alignment, because translation and rotation altered the pixel properties at the boundaries of the structures. Because left and right V1 do not differ in size (Zilles, 1978 b), only the total volume was calculated. Linear dimensions refer to measurements in the respective planar projections. All measurements were done in the $3 \mathrm{D}$ reconstructions at maximum resolution. Statistical analysis was performed with functions provided by Excel
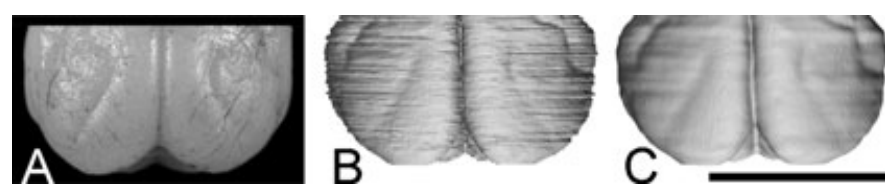

FIG. 2. The occipital part of a brain on P15 viewed from superior (A) and the corresponding reconstruction based on every fourth section at one-third of the original resolution (B), which was smoothed with a Gaussian filter (C). Scale bar, $10 \mathrm{~mm}$.
(Office XP 2003; Microsoft). Reconstructions were generated with the program Imaris version 4.2.0 (Bitplane). For illustration the reconstructions were smoothed (Fig. 2) with a Gaussian filter (width at 150).

\section{Results}

\section{Volume changes, alignment and resolution of sections}

Histological processing induced volume shrinkage, which was inversely correlated with age. The shrinkage factors (Table 1) determined for length, width and height of the hemispheres unveiled that the changes in the three planes differed. Therefore, in each animal, these factors were used to correct the shrinkage in all three planes individually.

Reconstruction and morphometry demand a proper alignment of the image stacks. Alignment was accomplished by sequential superposition of images of neighbouring sections, and translation and rotation until best matching of all outlines. To evaluate the 'geometric best fitting' the following approaches were performed with serial sections of different animals (P1, P15, P22, P45, P130): (a) automatic alignment (program KS 400) using primarily the midline of the sections and in addition the artificial landmarks as reference system; (b) manual alignment using primarily the landmarks, the midline and the maximal area of overlap of the brain structures as reference system (Autoaligner); and (c) automatic alignment by consistent matrix transformation (Autoaligner). The outcome was judged on 3D reconstructions by means of morphognostic and morphometric criteria: (i) course of the internal landmarks; (ii) comparisons of shape and size of reconstructions with photographs of the brains (Fig. 2); and (iii) consistency and continuity of the appearance of reconstructed structures (V1, the visual pathway and ventricles). It turned out that procedure (b) was the method of choice, and all series were processed accordingly.

Reliability and validity of $3 \mathrm{D}$ reconstructions depend also on the resolution of the digitized images and section thickness. The influences were estimated using a complete series of 333 sections at a thickness of $20 \mu \mathrm{m}$ (corrected: $24.83 \mu \mathrm{m}$ ) of the P15 animal. At first we reduced the resolution of the section plane (pixel size: $\mathrm{X}=11.64 \mu \mathrm{m}, \mathrm{Y}=12.33 \mu \mathrm{m}$ ) gradually to $1 / 10$ of the original scans. It turned out that the volume of V1 remained unchanged. Secondly, when we decreased the resolution along the Z-axis (section thickness or distance, respectively) using only every second, third, fourth, ..., 10th section, the volume of V1 remained unchanged until including up to every eighth section. The reconstruction reproduced very closely the original shape and dimensions of the brain (Fig. 2). Thus, to reduce the effort in time, amount of computational and storage capacity for reconstructions without significant loss of information, the resolution in $\mathrm{X}$ and $\mathrm{Y}$ was reduced to one-third, in $\mathrm{Z}$ to one-eighth in animals older than P22, whereas the small size of internal brain structures in younger animals required for reconstruction every fourth section.

\section{Growth of the occipital neocortex}

On P1, the occipital poles reached the anterior surface of the otherwise freely exposed superior colliculi. At that age, the total length of the hemispheres measured about $10.3 \mathrm{~mm}$. The neocortex expanded posteriorly, overgrew gradually the midbrain and approached eventually the cerebellum until the end of the third postnatal week (Fig. 3). On P22, the length of the hemispheres measured $19.5 \mathrm{~mm}$. It increased further to $21.3 \mathrm{~mm}$ on P45 and was afterwards reduced by $6.1 \%$ to $20 \mathrm{~mm}$ (Table 2). Hence, the total length of the hemispheres 

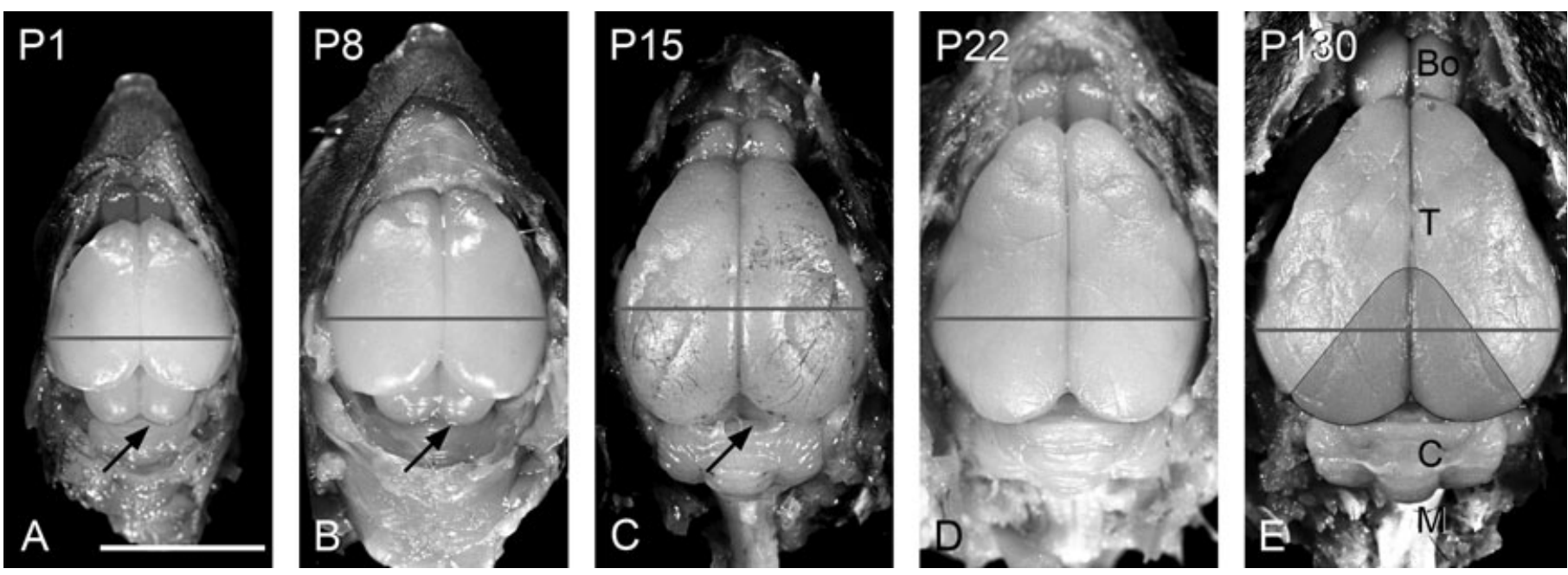

FIG. 3. Dorsal view of brains in situ of 1-, 8-, 15-, 22- and 130-day-old tree shrews. (A-D) The period during which the enlarging telencephalic hemispheres (T) progressively overlie the superior colliculi (arrows). The nearly freely exposed colliculi on P1 are completely concealed at the beginning of the fourth postnatal week (P22). (E) The region of the neocortex that harbours V1 (grey area). The line across the telencephalic hemispheres indicates the site of their maximum width. Abbreviations: Bo, olfactory bulb; C, cerebellum; M, medulla oblongata; T, telencephalon. Scale bar, $10 \mathrm{~mm}$.

TABLE 2. Morphometric data of investigated animals

\begin{tabular}{|c|c|c|c|c|c|c|c|c|}
\hline \multirow[b]{2}{*}{$\begin{array}{l}\text { Age } \\
\text { (postnatal } \\
\text { day) }\end{array}$} & \multicolumn{4}{|l|}{ Brain } & \multicolumn{4}{|l|}{ V1 } \\
\hline & $\begin{array}{l}\text { Length } \\
(\mathrm{mm})\end{array}$ & $\begin{array}{l}\text { Height } \\
(\mathrm{mm})\end{array}$ & $\begin{array}{l}\text { Max. } \\
\text { width } \\
(\mathrm{mm})\end{array}$ & $\begin{array}{l}\text { Volume } \\
\left(\mathrm{mm}^{3}\right)\end{array}$ & $\begin{array}{l}\text { Length } \\
(\mathrm{mm})\end{array}$ & $\begin{array}{l}\text { Max. } \\
\text { width } \\
(\mathrm{mm})\end{array}$ & $\begin{array}{l}\text { Surface } \\
\left(\mathrm{mm}^{2}\right)\end{array}$ & $\begin{array}{l}\text { Volume } \\
\left(\mathrm{mm}^{3}\right)\end{array}$ \\
\hline 1 & 10.3 & 9.3 & 11.5 & 755.1 & 5.8 & 8.0 & 62.4 & 22.4 \\
\hline 7.1 & 13.0 & 9.3 & 13.0 & 1016.5 & 7.3 & 9.4 & 91.3 & 41.4 \\
\hline 7.2 & 15.0 & 11.5 & 15.3 & 1645.7 & 6.6 & 10.5 & 110.9 & 58.4 \\
\hline 10 & 17.1 & 12.7 & 15.7 & 1878.0 & 6.4 & 10.7 & 124.6 & 73.4 \\
\hline 11 & 15.0 & 10.3 & 15.0 & 1113.3 & 6.3 & 10.9 & 96.5 & 46.1 \\
\hline 15 & 16.4 & 12.7 & 16.1 & 1936.1 & 8.0 & 11.6 & 152.0 & 101.2 \\
\hline 16 & 14.0 & 11.8 & 16.0 & - & 7.9 & 11.1 & 148.7 & 80.0 \\
\hline 20 & - & 13.1 & 17.7 & 2420.1 & 7.6 & 11.1 & 168.3 & 97.9 \\
\hline 22 & 19.5 & 15.0 & 18.5 & 2516.9 & 7.2 & 12.9 & 192.4 & 144.6 \\
\hline 45 & 21.3 & 14.6 & 19.5 & 3291.4 & 8.2 & 12.4 & 200.5 & 163.3 \\
\hline 66 & 19.8 & 14.7 & 17.5 & 2952.6 & 8.9 & 11.6 & 203.2 & 171.4 \\
\hline 130 & 20.0 & 13.0 & 19.5 & 3291.4 & 7.7 & 12.7 & 162.9 & 119.5 \\
\hline
\end{tabular}

The brain volume was calculated by brain weight in grams divided by the specific gravity $\left(1.033 \mathrm{~g} / \mathrm{cm}^{3}\right.$; Zilles, 1978b). Measurements and statistical analyses were done with two-digit numbers and rounded off/up to one-digit numbers.

doubled nearly from P1 to adulthood. Simultaneously, the poles descended and the slope increased with age (details below).

The growth of the occipital part of the hemispheres was estimated by two approaches. Firstly, the distance between the intra-aural line and the occipital pole was measured with the stereotactic apparatus on P7, P10, P22 and P130. It increased from about $1.14 \mathrm{~mm}$ on P7 to $1.68 \mathrm{~mm}$ on P10, $2.0 \mathrm{~mm}$ on P22, and to $2.02 \mathrm{~mm}$ on P130. Thus, the total increase during this period amounted to $177 \%$, whereas the hemispheric part anterior to the intra-aural line increased by $129 \%$ only. Secondly, the length of the visible superior colliculi was measured on P1, P22 and P130. It increased from $3.3 \mathrm{~mm}$ on P1 to $4.2 \mathrm{~mm}$ on $\mathrm{P} 22$, and reached $5.9 \mathrm{~mm}$ in the adult. Taking into account the parts of the colliculi that were covered on P1 by the poles, the extension of the poles amounted to $3.8 \mathrm{~mm}$ (without considering the rotation). Thus, it surpassed significantly that of the hemispheres and amounted to nearly $40 \%$ of the total increase of the hemispheric length.
The height and the maximum width of the hemispheres increased rapidly until P22 by about $160 \%$. Thereafter, the height decreased by nearly $13 \%$, whereas the maximum width enlarged further until P45 to $170 \%$ of the value on P1 and remained constant from then on (Table 2). The position of the maximum width shifted slightly with age (Fig. 3). Consequently, with the growth in all dimensions, the volume of the whole brain enlarged significantly. It amounted to $755 \mathrm{~mm}^{3}$ on $\mathrm{P} 1$, increased exponentially until $\mathrm{P} 22$ by $333 \%$, reached its maximum value of $3291 \mathrm{~mm}^{3}$ on $\mathrm{P} 45$, and remained approximately constant until P130 (Table 2). Thus, the brain volume increased from P1 to adulthood by $436 \%$. Regression and correlation analyses indicated a strong relationship between brain volume and age (Fig. 4A). The reliability of the trend line (coefficient of determination or $R^{2}=0.82$ ) was probably influenced by the sample size and the great individual variability. The brain volume of the two P7 animals differed significantly, and the volume on P11 was much smaller than on P10.

The lateral ventricles, continuous with the third ventricle at the rather wide interventricular foramen, were nearly $\mathrm{C}$-shaped on $\mathrm{P} 1$. The temporal horn was not yet directed towards the anterior (Fig. 5C). Simultaneous with the growth of the hemispheres the ventricles enlarged in size (Fig. 5A), shifted laterally, continued to grow in a curve direction, and the temporal horns expanded eventually towards frontal. On P16, a small protrusion appeared at the posterior end of the ventricles that became more distinct with age, indicating an incipient occipital horn (Fig. 5A). It was turned slightly toward medial and located inferior to V1 (Fig. 5B).

\section{Development of $\mathrm{V} 1$}

On P1, the future V1 could be discerned by its conspicuous granular layer IV that ceased rather abruptly at the area boundaries. On the superior surface it demarcated a crescent-like region that reached from a point anterior to the interventricular foramen to the occipital poles (Fig. 5C). The poles were completely concealed and the area boundary converged from there on the inferior surface towards the midline further anteriorly. It extended along the medial surface and approached anteriorly the superior margin. The laminar pattern was rather immature (Fig. 6A-F). Layer I was clearly delineated, layers II and III could not be distinguished, and layer IV was differentiated into its 

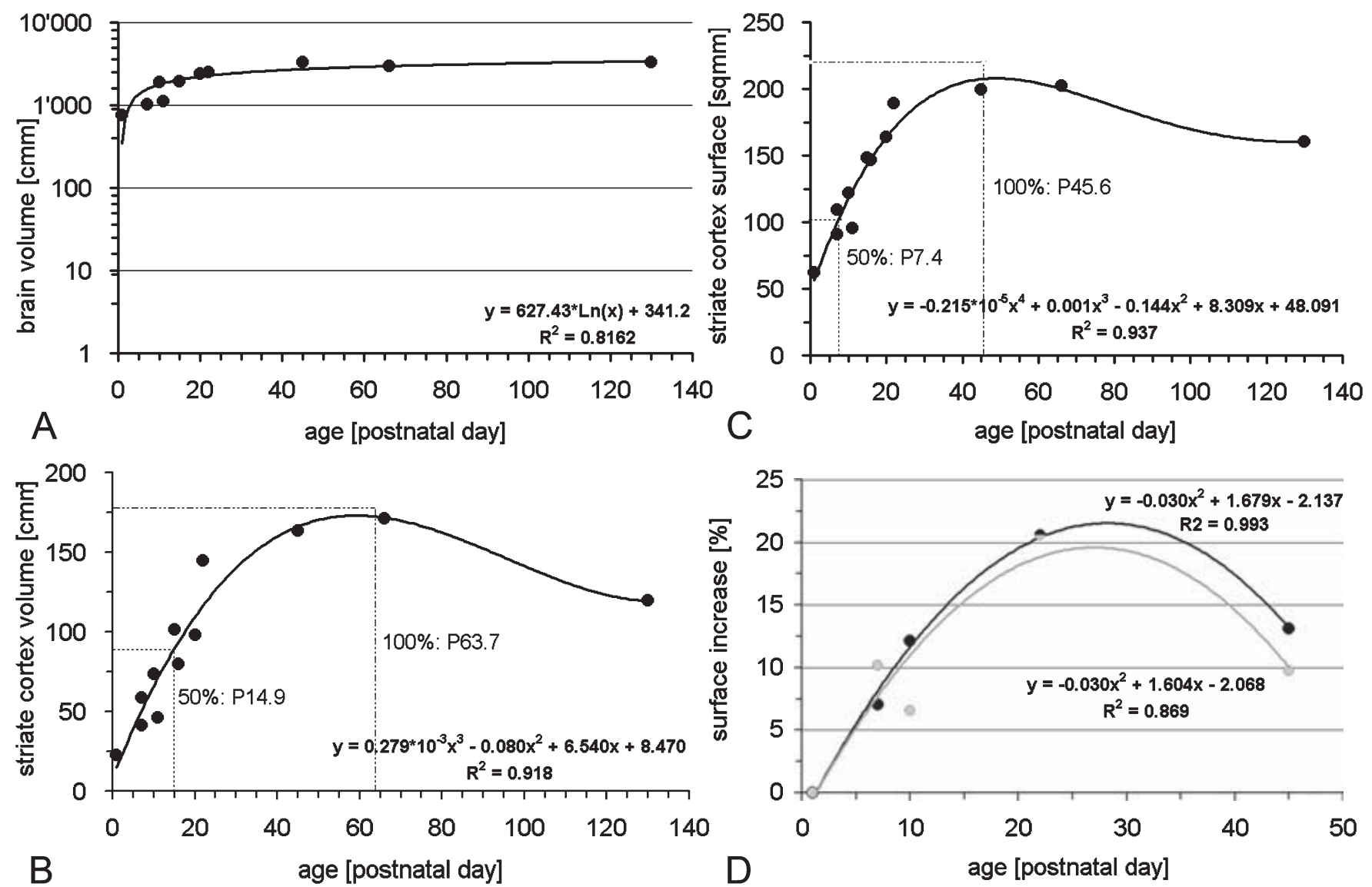

FIG. 4. Statistical analyses. (A) The diagram describes the increase of the logarithmic volume of the tree shrew brain from P1 to P130. (B) The diagram depicts the changing volume of V1. According to the polynomial trend-line, the volume increased exponentially until about P22 and reached its maximum (100\%) on P63.7; thereafter the volume decreased by about $30 \%$ to the adult value. On P14.9, $50 \%$ of the maximum volume was reached. (C) The diagram shows the developmental changes of the external surface area of V1 from P1 to P130. The polynomial trend-line indicates the developmental course: the surface enlarged exponentially until about P22, the half-value age was P7.4, the maximum was reached on P45.6; thereafter the surface area decreased by about $20 \%$ to the adult value. (D) The diagram depicts the increase of the superior (black filled circles) and inferior (grey filled circles) surface of V1 from P7 to P45 as a percentage of the total increase during this period. The survey was based on the projected outlines of the respective surfaces shown in Fig. 8A. $y=a+b X+c X^{2}+d X^{3}+e X^{4}(X=$ postnatal day) signifies the equation of the polynomial trend-line, $R^{2}=$ coefficient of determination.

sublayers only in about the midst of the demarcated region close to the superior margin (Fig. 6B and E). V1 enlarged with age, and the differentiation of layer IV proceeded towards the periphery. From P7 onward, the poles showed a clear subdivision of layer IV (Fig. 6G). Within the periphery layer IV remained undifferentiated. On that day, layer IIIc was discernable. The whole V1 was elongated, and laterally and medially enlarged (Fig. 7). On the inferior surface it covered posteriorly a narrow, crescent-like region.

During the second week, V1 started to shift posteriorly relative to the interventricular foramen, and its anterior border located eventually behind the foramen as shown in the adult (Fig. 5D). The expansion of V1 continued and its lateral extension entailed that its shape on the superior surface appeared triangular from P10 onward (Fig. 7). The crescent on the inferior surface was elongated and enlarged. On P14, layers III and II were distinguishable in the central region (Fig. 6H), layer IV was subdivided up to the inferior border of the medial wall. On P15, V1 concealed about three-quarters of the medial surface and approached anteriorly the superior margin. The thickness of V1 was significantly increased and, compared with P14, the bigger size of the medial wall indicated that some intrinsic growth occurred in the already formed cortex (Fig. 6I). In about the central region of the anterior-posterior extension of the demarcated region, a subdivided layer IV was found on the superior side within about $70 \%$ of its whole extension, extended across the medial wall to the adjacent inferior surface. There, the newly appearing V1 never showed the characteristic subdivision of layer IV (Fig. 1). From about P22 onward, V1 concealed the medial surface and the adjacent inferior side, except for the anterior $4 \%$ of its entire extension. The cortex on the inferior side elongated and expanded laterally simultaneously with the ongoing extension and maturation on the supero-lateral surface. Thereby, its crescent-like shape enlarged continuously but never reached the lateral level of the superior surface (Fig. 7). On P66, the extension of V1 corresponded greatly with that found on P45 with the exception of its slightly increased length. Thereafter, V1 appeared to be expanded only along the lateral periphery of the inferior surface (compare P45 with P130 in Fig. 7). In the adult, the conspicuous granular layer IV, subdivided into two compact sublayers IVa and IVb, extended from the lateral supero-lateral boundary of V1 up to the inferior surface adjacent to the medial wall. All other parts on the inferior surface presented a small and undifferentiated layer IV (Fig. 1). During the whole period, V1 on both hemispheres spread and maturated symmetrically in time and space. The poles enlarged laterally, which entailed that the distance between the poles increased from P1 to adulthood by about $25 \%$. The angle between the poles remained unchanged during development (Fig. 8). A calcarine sulcus was not observed. 

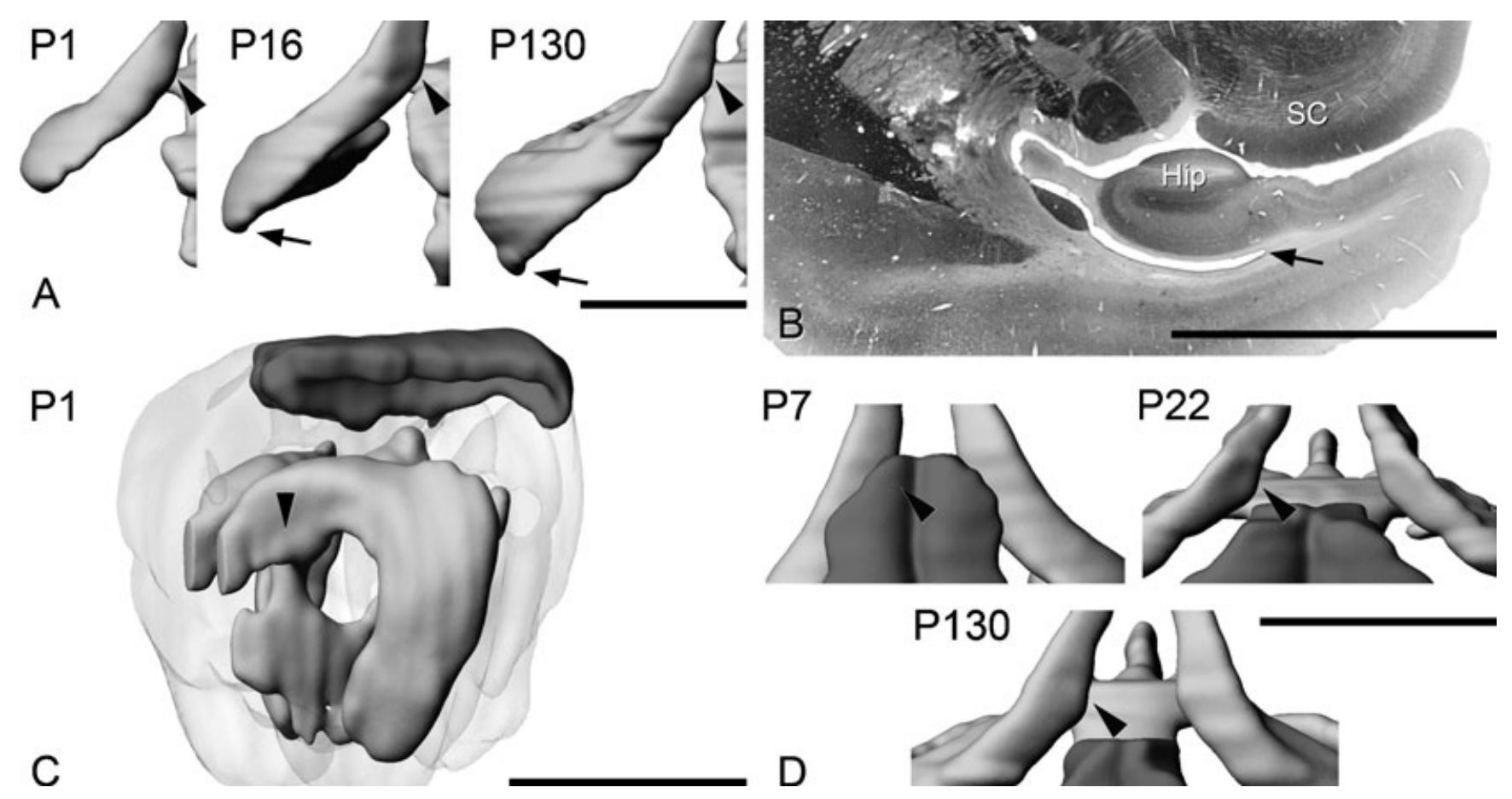

FIG. 5. (A) 3D reconstructions of the left lateral ventricle on P1, P16 and P130 viewed from superior. Note the protrusion at the posterior end of the ventricle (arrows). The arrowheads indicate the site of the left interventricular foramen. Anterior is up and medial to the right side. (B) Horizontal section of an adult brain, stained with cytochrome oxidase histochemistry, cut at the level of the occipital horn of the lateral ventricle (arrow) through the hippocampus (Hip) and the superior colliculus (SC). Note that the occipital horn locates below V1 and lateral to the colliculus. (C and D) The shifting of V1 behind the interventricular foramen on P1, P7, P22 and P130. On P1, the cortex (dark grey) covered already the occipital poles as shown in an oblique lateral view (C) and extended to a point anterior to the interventricular foramen (position marked with an arrowhead; ventricles in light grey). (D) Superior views of the region of interest in reconstructions on P7, P22 and P130. During the second week, V1 started to shift posteriorly relative to the interventricular foramen, and at the beginning of the fourth postnatal week its anterior border located behind the foramen. Scale bars, $5 \mathrm{~mm}$.

The pattern of spreading or the increments on the superior and inferior surface became apparent by superposing the borderline of V1 of different ages (Fig. 8). At each age, the extension of V1 was significantly larger on the superior than on the inferior surface. On both sides V1 spread with age towards the periphery. Consequently, the external surface of $\mathrm{V} 1$ increased significantly. It amounted to $62 \mathrm{~mm}^{2}$ on P1, increased exponentially until about P22, and approached the highest value of $203 \mathrm{~mm}^{2}$ on P66. Thereafter, it decreased by about $20 \%$ to the adult value of $163 \mathrm{~mm}^{2}$. The developmental course of the surface enlargement was described with a polynomial trend-line. According to this analysis, the maximum surface area was already reached on P45.6, $50 \%$ of it on P7.4 (Fig. 4C). Thus, the decrease started from P46 onwards. The squared coefficient of correlation $\left(R^{2}=0.932\right)$ indicated that nearly $95 \%$ of the growth related to age. Until P7, the increments on the superior and inferior surface were similar; from P7 onward they were larger on the superior surface (Fig. 4D). These measurements were based on the projections of the outlines of V1 shown in Fig. 8. Because the curvatures of the superior and inferior surface were similar, the relative difference should sufficiently describe the incremental growth.

In the adult, the shape of the occipital poles and of its white matter indicated a downward slope (Fig. 9A-C). To verify this impression, the anterior- and posterior-most points of $\mathrm{V} 1$ were interconnected with a line and the angle of this line was measured in reference to the Frankfurter horizontal plane (Fig. 9D). On P1, the angle amounted to about $3^{\circ}$, it increased gradually until P22 to about $9^{\circ}$, and it was $12^{\circ}$ in the adult. As a consequence of this descent the posterior poles eventually became located below the level of the callosal body.
Length, maximum width and volume of V1 showed similar developmental courses. The length of V1 was $5.8 \mathrm{~mm}$ on P1, increased until P22 by $125 \%$, and reached a maximum on P66 of $8.9 \mathrm{~mm}$. On P130, it was reduced by $13.5 \%$ compared with P66 to $7.7 \mathrm{~mm}$ (Table 2). Thus, the relative increase was similar to that of the hemispheres but less than the expansion of the occipital poles. The maximum width of $\mathrm{V} 1$ was always found slightly anterior to the occipital poles. On P1 the maximum width was $8.0 \mathrm{~mm}$ and it increased until P22 by about $160 \%$ to $12.9 \mathrm{~mm}$. Thereafter, a small decrease occurred. These enlargements were reflected by the volume of V1. It was $22.4 \mathrm{~mm}^{3}$ at birth (Table 2), increased exponentially until P22 by about $650 \%$ to $144.6 \mathrm{~mm}^{3}$, and approached a highest value of $170.1 \mathrm{~mm}^{3}$ on P66 (761.5\%). On P130 the volume was decreased by $29.6 \%$ to $119.5 \mathrm{~mm}^{3}$. Despite this decrease, the volume growth of V1 outnumbered that of the whole brain. The corresponding polynomial trend-line $\left(R^{2}=0.92\right)$ indicated that the maximum volume was reached on P63.7, the half-value age was on P14.9 (Fig. 4B). The individual variability in size observed in the brain volume occurred also in V1 (Table 2).

\section{Discussion}

The development of V1 began on the superior and supero-medial surface of the occipital neocortex. It covered the poles already on P1. The differentiation of the laminar pattern was advanced in about the central region of the demarcated region. There the granular layer IV was subdivided by a cell-sparse cleft into two sublayers. Until adolescence, V1 spread and maturated in a centro-peripheral 


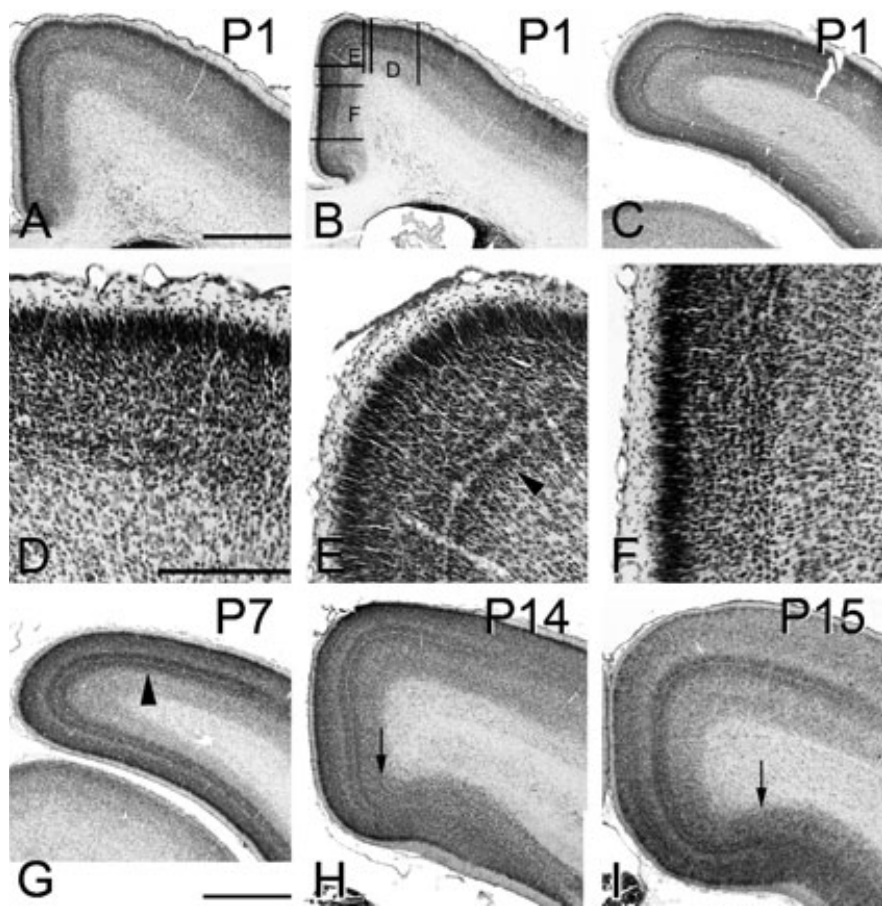

FIG. 6. The light microscopic micrographs of frontal sections (corrected for shrinkage) through V1 on P1, P7, P14 and P15 demonstrate the development of the lamination pattern. The mid-sagittal plane of the brain is to the left. (A-C) On P1 the lamination pattern in the central region of V1 (B) is more differentiated (arrowhead) than the regions further anterior (A) or posterior (C). The letters (D-F) in (B) indicate the positions from where the magnifications in panels (D-F) are made. The arrows mark the borderline of V1. (G) On P7, lamina IV is already subdivided into its two sublayers (arrowhead) in the region close to the poles. $(\mathrm{H})$ On P14, the differentiated layer IV had reached the inferior border of the medial wall. (I) On the next day the overall dimensions of the medial wall were increased. The differentiation of layer IV has proceeded onto the inferior surface shifting area 18 toward lateral, as shown in the central region of V1. Scale bars, $1 \mathrm{~mm}$ (A-C and G-I); $0.25 \mathrm{~mm}$ (D-F).

topographic gradient. The differentiated layer IV reached the inferior surface on P15. The newly formed cortex on this side presented a layer IV that did not show any sublayers. Until P46, V1 on the superior and inferior surface elongated, enlarged laterally and decreased then by about $20 \%$ to the adult value. During the whole period the external surface increased by $261 \%$. The volume increased about twice as much. It approached its maximum size slightly later during adolescence, and was reduced by about $30 \%$ in the adult. During the first three postnatal weeks, the whole V1 shifted posteriorly, the poles covered eventually the midbrain and descended below the level of the callosal body. The enlargement of the occipital parts of the hemispheres was accompanied by a posterior extension of the lateral ventricles.

\section{Technical considerations}

The dimensions of the sections or brains, respectively, were corrected for volume changes caused by the histological processing but not for shrinkage induced by fixation. Thus, the reported sizes were probably underestimated. In addition, the data came from a small sample of domesticated animals. Domestication is usually associated with a decrease in brain size, especially of the sensory centres (Kruska, 2005). The brain size of wild Tupaia belangeri is unknown. The observed brain volume in the adult of $3.3 \mathrm{~cm}^{3}$ and those during development corresponded rather well with the values reported by Zilles (1978b) for animals also reared in captivity.

The artificial landmarks generally allowed a proper alignment of the serial sections, although their shape and positions could vary to some extent. In the P1 animal the image stack was registered by best matching of structure contours, as landmarks could not be applied. This approach bears the danger that curved structures become straightened. The inclusion of additional structures served to minimize this effect. The erratic appearance of the lateral boundaries of V1 in the $3 \mathrm{D}$ reconstructions resulted mainly from the section distance.

\section{Comparison with earlier studies on $\mathrm{V} 1$ in tree shrews}

The topography of V1 in adult tree shrews confirmed earlier reports (Diamond et al., 1970; Zilles, 1978a; Kaas, 1980; Frahm et al., 1984). The observed topographically varying thickness of V1, the thickness and particularly the structure of the retino-recipient layer IV distinguishes the functional subdivision of V1: the binocular and the monocular part (Wong-Riley \& Norton, 1988). Based on these criteria, the binocular part can be identified across the supero-lateral surface of V1 up to the inferior surface adjacent to the medial wall. From there the monocular part extended towards the lateral boundary of the inferior surface. This topography matched the findings of optical imaging techniques and electrophysiological recordings (Kaas, 1980; Bosking et al., 2000), depicted in Fig. 10A, C and D.

The volume of V1 and its growth has been studied by Zilles and his group (Nitschke, 1977; Zilles, 1978b). The comparison unveils some small, yet expected deviations because of differences in the applied histological and morphometric techniques, individual variability in size and in the progress of development, and effects caused by the small samples. Significant differences, however, existed in the size at its maximum (reported for P48) and in the adult where the values of Zilles (1978b) exceeded ours by about $32 \%$ despite similar brain sizes. This might result from the above-mentioned effects, particularly the interindividual variability must be emphasized. Despite this difference, the general developmental course of V1 volume was in accord with Zilles (1978b). During a first phase, its size increased exponentially, approached a maximum during adolescence and decreased thereafter by about $30 \%$ to the adult volume.

Growth curves that decline significantly after culmination are supposed to indicate a so-called overshooting growth. It is agreed that the surplus is reduced to some extent by programmed cell death. This joint operation is a widespread phenomenon during development of the nervous system and is considered important for the proper structural and functional architecture (Simon \& O'Leary, 1992; Wolff \& Missler, 1993; Blaschke et al., 1998; Clarke et al., 1998; de la Rosa $\&$ de Pablo, 2000). In primary visual centres, overshooting growth or apoptosis, respectively, was frequently observed and comprehensively described also in primates including humans (Fritschy \& Garey, 1986a,b; Klekamp et al., 1991; Zielinski \& Hendrickson, 1992; Missler et al., 1993a,b; Barone et al., 1995; Rabinowicz et al., 1996). In tree shrews, overshooting growth occurs in the pulvinar and the dorsal lateral geniculate nucleus (Kip, 1978; Zilles, 1978b), the main source of afferents to the primary visual cortex. In V1, Ungersböck et al. (1991) could not detect signs of apoptosis, which, however, is due to the fact that the critical age interval between P42 and adulthood was not investigated. Zilles and his group (Nitschke, 1977; Zilles, $1978 \mathrm{~b}$ ) showed that the volume of individual layers decreased up to $64 \%$ during adolescence. Thus, the available information suggests that the observed size reduction of V1 was not an artefact but was probably to a great extent caused by apoptosis (Zilles, 1978b). 
P1
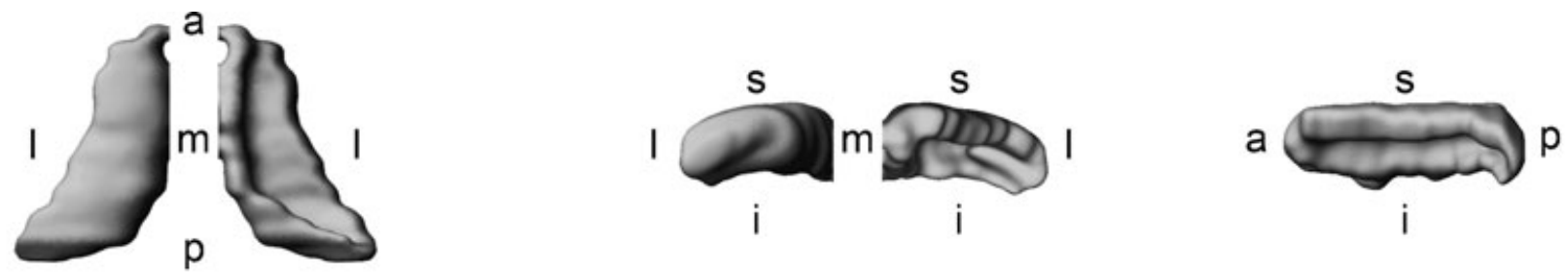

P7
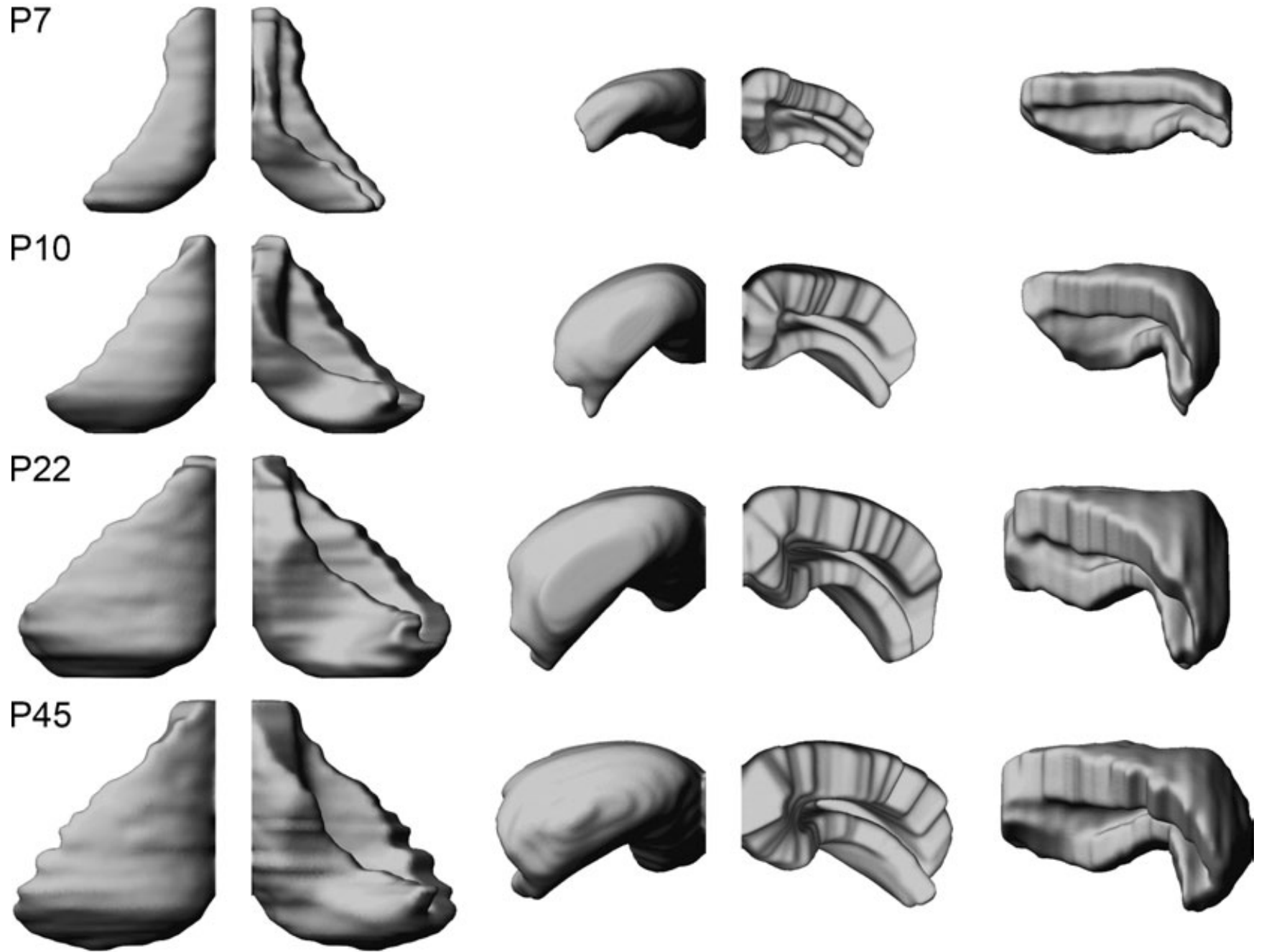

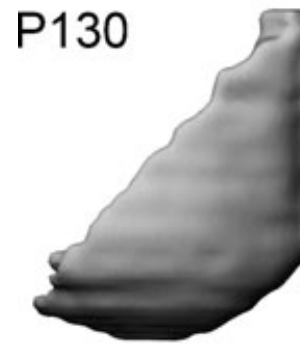

superior

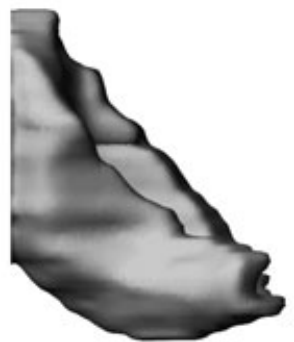

inferior

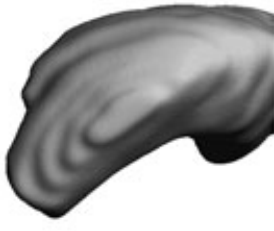

posterior

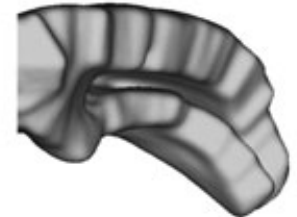

anterior

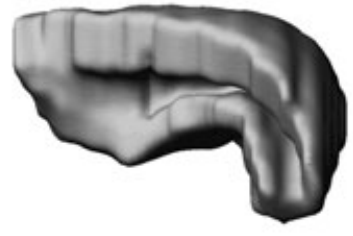

lateral

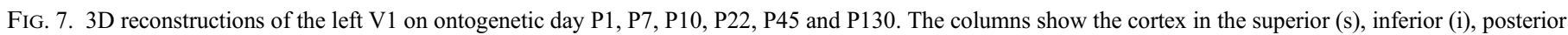

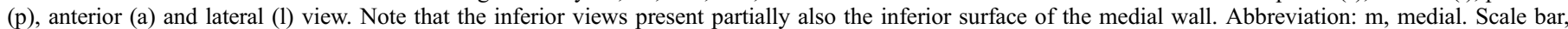
$5 \mathrm{~mm}$.

\section{The expansion of $V 1$}

The temporal and spatial course of the expansion of V1 is described here for the first time. Zilles (1978b) recognized a poorly defined V1
4 days before birth. On P1, the layering pattern, although rather immature, allowed to demarcate the future V1. Its granular layer IV occupied a crescent-like region on the superior surface of the occipital cortex which, different to Zilles (1978b) observation, included the 


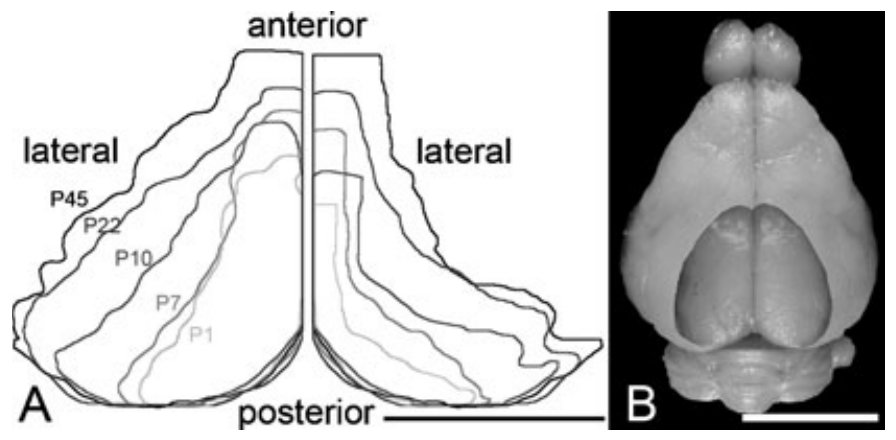

FIG. 8. (A) Superposed projections of the outlines of the left V1 in the superior (left side) and inferior view (right side) shown in Fig. 7 on P1, P7, P10, $\mathrm{P} 22$ and P45. The outlines were aligned in reference to the median-sagittal plane and the occipital poles. (B) The correspondingly superposed superior views of the brain on P1 and P130 demonstrate that the angle between the poles remained unchanged with development. Scale bars, $5 \mathrm{~mm}$.
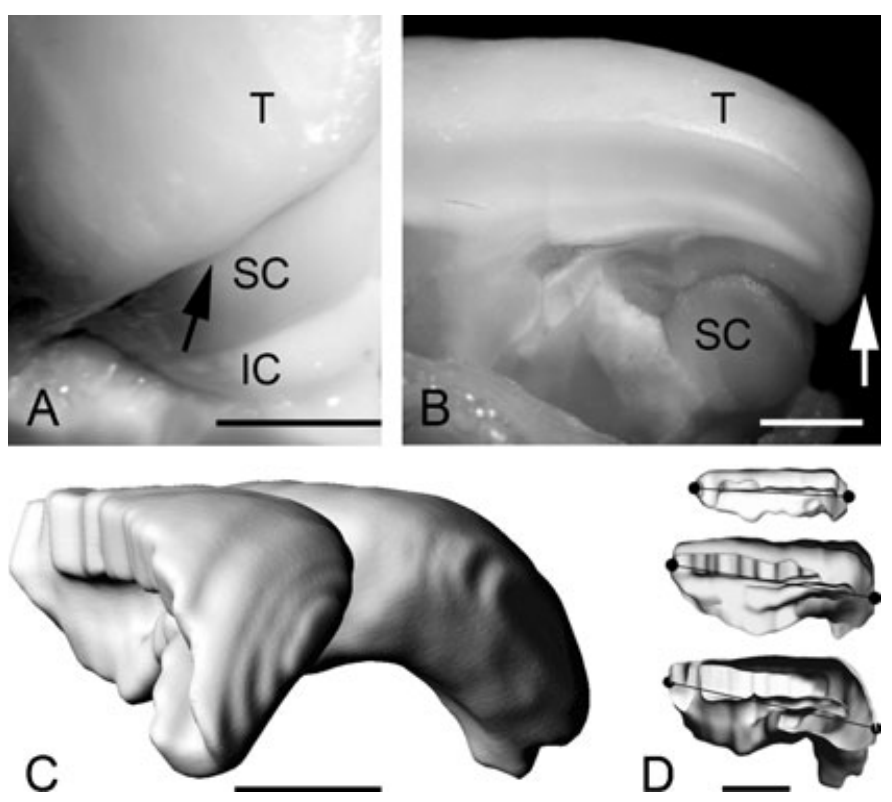

FIG. 9. The images show the occipital pole in tree shrews. (A and B) Photographs from an adult animal in an oblique supero-posterior (A) and in a lateral view of a sagittal cut though the occipital region (B). (C) The downward slope of the occipital pole in the reconstructed V1 on P130 in an oblique postero-lateral view. (D) 3D reconstructions of $\mathrm{V} 1$ on P1, P20 and P130 in a lateral view. The black line interconnects the anterior- and posterior-most points of V1. Its angle was measured in reference to the Frankfurter horizontal plane. Abbreviations: IC, inferior colliculus; SC, superior colliculus; T, telencephalon. Scale bars, $5 \mathrm{~mm}$.

occipital pole. In the central part of V1, in the region of the superior margin, layer IV was divided by a cell-sparse cleft into two small sublayers. This subdivision identified the developing binocular part. With age, V1 extended tangentially into all directions and increased in thickness. The laminar pattern maturated in a central to peripheral gradient and progressed within a given region along the radial axis of the cortex in the earlier-described 'inside-out' gradient (Rakic, 1982). The differentiation of layer IV had reached the occipital poles on P7. On P15, in about the central region of V1, layer IV was subdivided within about three-quarters of its supero-lateral extension up to the inferior surface adjacent to the medial wall. The latter site corresponded to the medial margin of the binocular part (Kaas, 1980). The granular layer IV of the newly formed cortex on the inferior side did not differentiate into compact sublayers. This configuration is a distinctive feature of the monocular part, and this allows us to time its appearance (on P15). V1 continued to expand on both surfaces until adolescence. The expansion of the monocular part ceased after the binocular part had reached its supero-lateral boundary. The external surface of V1, which amounted to about $62 \mathrm{~mm}^{2}$ on P1, enlarged exponentially until P22, approached its climax on P46, and decreased then by about $20 \%$ to the adult value of $163 \mathrm{~mm}^{2}$. Thus, it increased by more than $260 \%$. The enlargement resulted mainly from the spreading of $\mathrm{V} 1$, but there was evidence that some growth occurred within the already formed cortex. The survey of the investigated ages indicated that the development and maturation started in about the central region of the future V1 (Fig. 10E and F). A similar topographic gradient of maturation was observed in V1 of marmoset monkeys by neurofilament immunohistochemistry (Bourne et al., 2005).

\section{Developmental implications}

The primary visual cortex of tree shrews is visuotopically organized preserving the topographic relationship of retinal ganglion cells at a fine scale (Kaas et al., 1972; Kretz et al., 1986; Bosking et al., 2000, 2002). This poses the question about the pattern of appearance of cortical regions in reference to the retinotopic map. The retinal topography along the dorso-ventral and temporo-nasal axis is imaged in V1 along its antero-posterior axis and from the supero-lateral boundary of the binocular to the infero-lateral boundary of the monocular part (Fig. 10A, C and D). The border between the bi- and monocular part corresponds approximately to the $30^{\circ}$ isoazimuth line, the horizontal meridian separates dorsal and ventral retina (Kaas, 1980). It passes through area centralis retinae where it crosses the vertical meridian (which subdivides the binocular part into an ipsi- and contralateral visual field; Bosking et al., 2000). The retinotopic map reflects also the ganglion cell density (Fig. 10). It is highest in the binocular part adjacent to the horizontal meridian with a peak in area centralis retinae and decreases toward the periphery with a steep temporal gradient (DeBruyn, 1983).

In reference to the retinotopic map V1 developed in a manner by which the central to peripheral image of the neural retina emerged in a coherent temporo-spatial sequence (Fig. 10E and F). The binocular part was identified at first. It appeared on $\mathrm{P} 1$ in a region representing approximately the central retina close to the $20^{\circ}$ isoazimuth line, which corresponds to the visual streak in the adult (DeBruyn, 1983). From there V1 spread into all directions, the region that relates to area centralis retinae appeared and the binocular part reached its medial border on P15. There the monocular part started to extend and eventually the areas representing the nasal periphery emerged. Similarly, in marmoset monkeys, the topographic pattern of V1 maturation mimics the centro-peripheral gradient of maturation of the neuronal retina, starting with the foveal representation (Bourne et al., 2005).

It is tempting to compare this developmental course with the central to peripheral gradient of maturation of the neuronal retina (Foelix et al., 1987). However, bilateral enucleation in primates prior to the ingrowths of geniculate afferents into the cortical plate and before genesis of the granular and supragranular layers had no impact on the laminar cytoarchitecture but on the size and location of V1 in the neonate (Rakic \& Lidow, 1995; Dehay et al., 1996). Thus, a direct link between retinal neurogenesis and development of V1 can not be established. But afferent systems seem to play a synergistic role in size, location and specification of the primary visual cortex (Wiesel, 1982; Rakic, 1988; Shatz, 1990). 

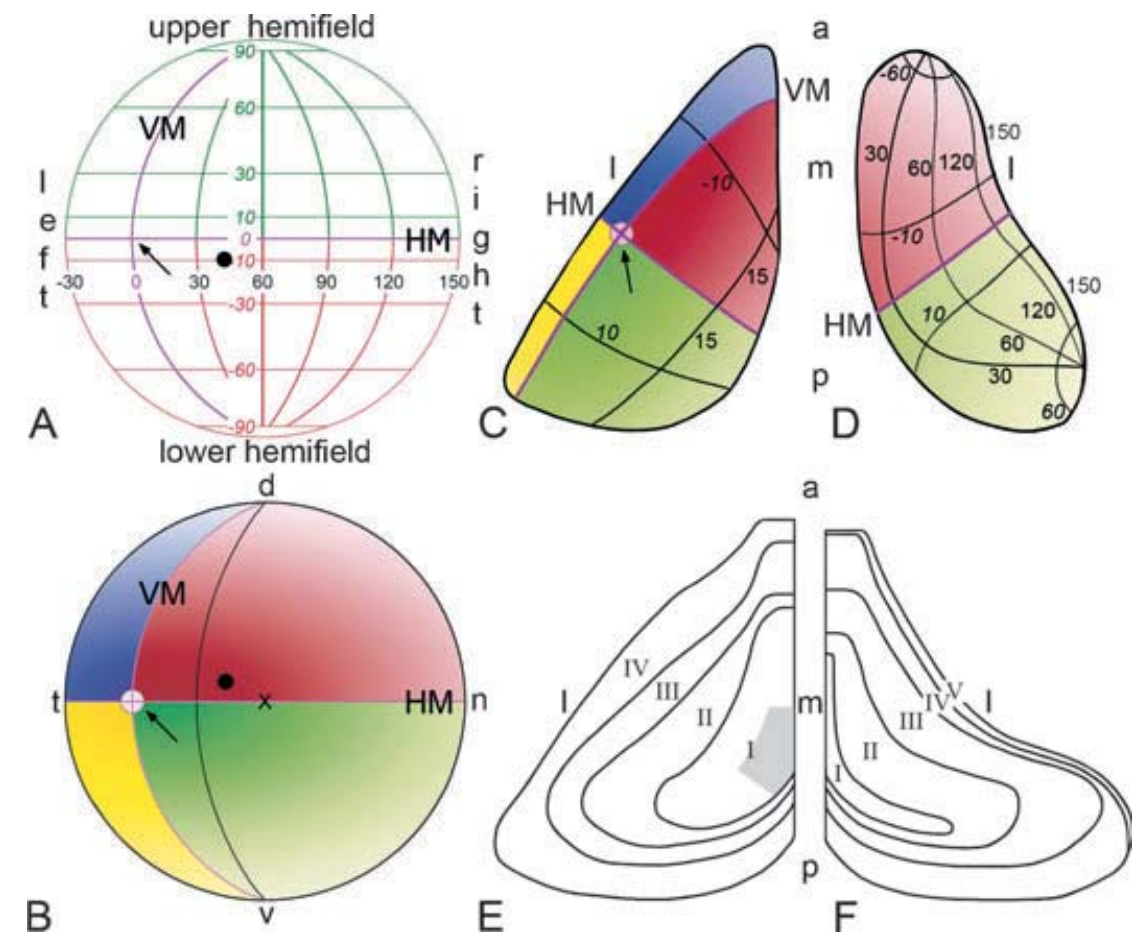

FIG. 10. Model of the temporo-spatial growth of V1 in relation to the visuotopic or retinotopic organization (Kaas et al., 1972; Bosking et al., 2000). (A) Planar view of the hemispheric representation of the visual space in the right eye, subdivided by isoazimuth and isoelevation lines. The vertical meridian (VM) delimits the ipsi- and contralateral visual field, the $\pm 30^{\circ}$ isoazimuth lines define the binocular part. The horizontal meridian (HM) separates the upper and lower hemifield, and crosses VM at area centralis retinae (arrow). This topology is conserved in the contralateral V1 depicted in a superior (C) and medio-inferior (D) view (modified according to Kaas, 1980; Bosking et al., 2000). The colours indicate the ipsilateral (blue and yellow region) and contralateral visual field (red and green) of the dorsal and ventral retina, respectively (B, right eye, anterior view). The topographically varying retinal ganglion cell density, indicated in (B) by graded colours, is reflected by the representation of the visual space in V1. The density is highest in the central retina with a peak in the area centralis retinae (arrow) and decreases towards the periphery with a steep gradient temporally (following DeBruyn, 1983). The black dot marks the optic disk and X the geometric centre of the retina. (E and F) A schematized left V1 in a superior (E) and medio-inferior view (F); the labelled regions (letters I-V) exemplify the expansion during development. It starts in a region that represents approximately the central part of the future primary visual cortex. The grey area in $(E)$ indicates the region where the bipolar part was identified shortly after birth. Until adolescence, V1 expands continuously into the periphery. Thus, compared with the retinotopic organization of $\mathrm{V} 1$, regions emerge in coherent succession representing the neuronal retina in a central to peripheral gradient. Abbreviations: a, anterior; $\mathrm{d}$, dorsal; 1, lateral; $\mathrm{m}$, medial; $\mathrm{n}$, nasal; $\mathrm{p}$, posterior; $\mathrm{t}$, temporal; $\mathrm{v}$, ventral.

\section{Impacts on the occipital neocortex}

The developmental changes of the primary visual cortex were reflected by the size and shape of the occipital part of the hemispheres. V1, which concealed the poles already on P1, elongated and expanded mainly laterally. The medial surface of the hemispheres and the angle between the poles remained almost unaffected. The poles enlarged laterally and the distance between the poles increased. Posteriorly, they reached the anterior surface of the superior colliculi on P1, expanded backward, and overgrew tightly the superior colliculi, which entailed a small downward slope. Thereby, the colliculi became completely covered at the end of the third postnatal week. The distance overgrown by the occipital part of the hemispheres was larger than the increase in length of V1. Thus, one might assume that the observed simultaneous translation of V1 contributed to the bridging of the mesencephalon. This shifting might have resulted from the simultaneous expansion of the neocortex, not least from the development of the neighbouring secondary and tertiary visual cortical areas.

On P1, the lateral ventricles were curved and extended from the anterior horn infero-anteriorly into the developing temporal lobe. This suggests that already before birth the expansion of the cerebral hemispheres induced a rotation of the hemispheres. The lateral ventricles, as other structures, continued to enlarge postnatally in a C-shaped manner. During the third postnatal week, with the expansion of the occipital part of the hemispheres, a moderate occipital horn appeared in the lateral ventricles.

\section{Conclusions}

The future V1 is already clearly demarcated on P1 on the superior surface and pole of the occipital cortex. From there V1 spreads into all directions, followed by the differentiation and maturation of its layers. In the temporo-spatial course of development, regions emerge that represent the central to peripheral neuronal retina in a coherent succession. The binocular part appears already on P1 in the central region of V1. The monocular part comes into view at the beginning of the third week, after the binocular part reaches its medial boundary. Both parts increase in thickness and enlarge mainly by spreading, but some growth occurs also within the already formed cortex. The growth is greatest until tree shrews open their eyes $(\mathrm{P} 18.8 \pm 2.1)$ and it culminates after weaning (P32-P37) before they become sexually mature (P103P112). Subsequently a decrease occurs, mainly caused by apoptosis (Zilles, 1978b). The development completes in the young adult.

V1 is surrounded by secondary and tertiary visual cortices (Killackey et al., 1971, 1972; Kaas \& Krubitzer, 1991). They maturate synchronously with V1 and contribute to the enlargement of the occipital cortex. Its posterior extension entails a backward shifting of V1. Translation and elongation of V1 bring the occipital part of the 
hemispheres above the superior colliculi, which become eventually covered by a downward rotation of the poles. Associated with the extension of the occipital part of the hemisphere, the lateral ventricle extends posteriorly and a small occipital horn evolves. This characterizes an incipient moderate 'true' occipital lobe, which harbours mainly cortices involved in visual functions (Diamond et al., 1970; Killackey et al., 1971; Kaas \& Krubitzer, 1991).

Hence, in view of the phylogenetic descent of tree shrews the observations may support the hypothesis that the progressive evolution of the visual system found in primates initiated in the early phase of development from insectivores to prosimians (Frahm et al., 1984).

\section{Acknowledgements}

We wish to thank Mrs Marguerite Kaczorowski, Mrs Marie-Jo Graber, and especially Ms Monique Carrel for excellent technical assistance, Mr Bernard Frei for his advice in digital imaging and reconstruction techniques. Thanks are particularly due to Mrs Sonja Simeonova, who did the perfusion fixation and preparation, supervised the sectioning, and made most of the photographs of the serial sections used in this study.

\section{References}

Barone, P., Dehay, C., Berland, M., Bullier, J. \& Kennedy, H. (1995) Developmental remodeling of primate visual cortical pathways. Cereb. Cortex, 5, 22-38.

Blaschke, A.J., Weiner, J.A. \& Chun, J. (1998) Programmed cell death is a universal feature of embryonic and postnatal neuroproliferative regions throughout the central nervous system. J. Comp. Neurol., 396, 39-50.

Böck, P. (1989) Romeis, Mikroskopische Technik. Urban \& Schwarzenberg, München.

Bosking, W.H., Crowley, J.C. \& Fitzpatrick, D. (2002) Spatial coding of position and orientation in primary visual cortex. Nat. Neurosci., 5, 874882.

Bosking, W.H., Kretz, R., Pucak, M.L. \& Fitzpatrick, D. (2000) Functional specificity of callosal connections in tree shrew striate cortex. J. Neurosci., 20, 2346-2359.

Bourne, J.A., Warner, C.E. \& Rosa, M.G. (2005) Topographic and laminar maturation of striate cortex in early postnatal marmoset monkeys, as revealed by neurofilament immunohistochemistry. Cereb. Cortex, 15, 740748.

Clarke, P.G., Posada, A., Primi, M.P. \& Castagne, V. (1998) Neuronal death in the central nervous system during development. Biomed. Pharmacother, 52, $356-362$.

Conley, M., Fitzpatrick, D. \& Diamond, I.T. (1984) The laminar organization of the lateral geniculate body and the striate cortex in the tree shrew (Tupaia glis). J. Neurosci., 4, 171-197.

de la Rosa, E.J. \& de Pablo, F. (2000) Cell death in early neural development: beyond the neurotrophic theory. Trends Neurosci., 23, 454-458.

DeBruyn, E.J. (1983) The organization and central terminations of retinal ganglion cells in the tree shrew (Tupaia Glis). PhD Thesis, Vanderbilt University Nashville, Tennessee.

Dehay, C., Giroud, P., Berland, M., Killackey, H. \& Kennedy, H. (1996) Contribution of thalamic input to the specification of cytoarchitectonic cortical fields in the primate: effects of bilateral enucleation in the fetal monkey on the boundaries, dimensions, and gyrification of striate and extrastriate cortex. J. Comp. Neurol., 367, 70-89.

Diamond, I.T., Snyder, M., Killackey, H., Jane, J. \& Hall, W.C. (1970) Thalamo-cortical projections in the tree shrew (Tupaia glis). J. Comp. Neurol., 139, 273-306.

Foelix, R.F., Kretz, R. \& Rager, G. (1987) Structure and postnatal development of photoreceptors and their synapses in the retina of the tree shrew (Tupaia belangeri). Cell Tissue Res., 247, 287-297.

Frahm, H.D., Stephan, H. \& Baron, G. (1984) Comparison of brain structure volumes in insectivora and primates. V. Area striata (AS). J. Hirnforsch., 25, 537-557.

Fritschy, J.M. \& Garey, L.J. (1986a) Quantitative changes in morphological parameters in the developing visual cortex of the marmoset monkey. Brain Res., 394, 173-188.
Fritschy, J.M. \& Garey, L.J. (1986b) Postnatal development of quantitative morphological parameters in the lateral geniculate nucleus of the marmoset monkey. Brain Res., 395, 157-168.

Glendenning, K.K., Kofron, E.A. \& Diamond, I.T. (1976) Laminar organization of projections of the lateral geniculate nucleus to the striate cortex in Galago. Brain Res., 105, 538-546.

Kaas, J.H. (1980) A comparative survey of visual cortex organization in mammals. In Ebbesson, S.O.E. (Ed.), Comparative Neurology of the Telencephalon. Plenum Press, New York, pp. 483-502.

Kaas, J.H., Hall, W.C., Killackey, H. \& Diamond, I.T. (1972) Visual cortex of the tree shrew (Tupaia glis): architectonic subdivisions and representations of the visual field. Brain Res., 42, 491-496.

Kaas, J.H. \& Krubitzer, L.A. (1991) The organization of extrastriate visual cortex. In Dreher, B. \& Robinson, S.R. (Eds), Vision and Visual Dysfunction. The Macmillan Press, Houndsmills, Basingstoke, Hampshire, UK, pp. 302323.

Killackey, H., Snyder, M. \& Diamond, I.T. (1971) Function of striate and temporal cortex in the tree shrew. J. Comp. Physiol. Psychol., 74, 1-29.

Killackey, H., Wilson, M. \& Diamond, I.T. (1972) Further studies of the striate and extrastriate visual cortex in the tree shrew. J. Comp. Physiol. Psychol., 81, 45-63.

Kip, G. (1978) [Qualitative and quantitative studies on the lateral geniculate body in an ontogenic series of male Tupaia belangeri]. J. Hirnforsch., 19, $345-370$.

Klekamp, J., Riedel, A., Harper, C. \& Kretschmann, H.J. (1991) Quantitative changes during the postnatal maturation of the human visual cortex. J. Neurol. Sci., 103, 136-143.

Kretz, R., Rager, G. \& Norton, T.T. (1986) Laminar organization of ON and OFF regions and ocular dominance in the striate cortex of the tree shrew (Tupaia belangeri). J. Comp. Neurol., 251, 135-145.

Kruska, D.C. (2005) On the evolutionary significance of encephalization in some eutherian mammals: effects of adaptive radiation, domestication, and feralization. Brain Behav. Evol., 65, 73-108.

Lund, J.S., Fitzpatrick, D. \& Humphrey, A.L. (1985) The striate visual cortex in the tree shrew. In Peters, A. \& Jones, E.G. (Eds), Visual Cortex, Vol. 3 Cerebral Cortex. Plenum Press, New York, pp. 157-205.

Martin, R.D. (1990) Primate Origins and Evolution: a Phylogenetic Reconstruction. Chapman \& Hall, London.

Missler, M., Eins, S., Merker, H.J., Rothe, H. \& Wolff, J.R. (1993a) Pre- and postnatal development of the primary visual cortex of the common marmoset. I. A changing space for synaptogenesis. J. Comp. Neurol., 333, $41-52$.

Missler, M., Wolff, A., Merker, H.J. \& Wolff, J.R. (1993b) Pre- and postnatal development of the primary visual cortex of the common marmoset. II. Formation, remodelling, and elimination of synapses as overlapping processes. J. Comp. Neurol., 333, 53-67.

Nitschke, C. (1977) [Qualitative and quantitative investigations of the area striata in an ontogenic series of male Tupaia belangeri]. J. Hirnforsch., 18, 89-113.

Olson, L.E., Sargis, E.J. \& Martin, R.D. (2005) Intraordinal phylogenetics of treeshrews (Mammalia: Scandentia) based on evidence from the mitochondrial 12S rRNA gene. Mol. Phylogenet. Evol., 35, 656673.

Rabinowicz, T., de Courten-Myers, G.M., Petetot, J.M., Xi, G. \& de los Reyes, E. (1996) Human cortex development: estimates of neuronal numbers indicate major loss late during gestation. J. Neuropathol. Exp. Neurol., 55, 320-328.

Rakic, P. (1982) Early developmental events: cell lineages, acquisition of neuronal positions, and areal and laminar development. Neurosci. Res. Program. Bull., 20, 439-451.

Rakic, P. (1988) Specification of cerebral cortical areas. Science, 241, 170176.

Rakic, P. \& Lidow, M.S. (1995) Distribution and density of monoamine receptors in the primate visual cortex devoid of retinal input from early embryonic stages. J. Neurosci., 15, 2561-2574.

Shatz, C.J. (1990) Impulse activity and the patterning of connections during CNS development. Neuron, 5, 745-756.

Simmons, M.T. (1981) Bearing of the diencephalon on the taxonomic status of the Tupaioidea. J. Hirnforsch., 22, 129-152.

Simon, D.K. \& O'Leary, D.D. (1992) Development of topographic order in the mammalian retinocollicular projection. J. Neurosci., 12, 12121232.

Starck, D. (1982) Vergleichende Anatomie der Wirbeltiere, Vol. 3: Organe Des Aktiven Bewegungsapparates, der Koordination, der Umweltbeziehung, Des Stoffwechsels und der Fortpflanzung. Springer, Berlin. 
Ungersböck, A., Kretz, R. \& Rager, G. (1991) Synaptogenesis in the primary visual cortex of the tree shrew (Tupaia belangeri). J. Comp. Neurol., 308, 491-504.

Wiesel, T.N. (1982) Postnatal development of the visual cortex and the influence of environment. Nature, 299, 583-591.

Wolff, J.R. \& Missler, M. (1993) Synaptic remodelling and elimination as integral processes of synaptogenesis. APMIS Suppl., 40, 9-23.

Wong-Riley, M.T. \& Norton, T.T. (1988) Histochemical localization of cytochrome oxidase activity in the visual system of the tree shrew: normal patterns and the effect of retinal impulse blockage. J. Comp. Neurol., 272, $562-578$.

Zielinski, B.S. \& Hendrickson, A.E. (1992) Development of synapses in macaque monkey striate cortex. Vis. Neurosci., 8, 491-504.

Zilles, K. (1978a) A quantitative approach to cytoarchitectonics. I. The areal pattern of the cortex of Tupaia belangeri. Anat. Embryol. (Berlin), 153, 195212

Zilles, K.J. (1978b) Ontogenesis of the visual system. Adv. Anat. Embryol. Cell Biol., 54, 3-138. 